\title{
Craniovertebral realignment for basilar invagination
}

Atul Goel

Department of Neurosurgery, King Edward VII Memorial Hospital and Seth G.S. Medical College, Parel, Mumbai, Maharashtra, India

\section{A B S T R A C T}

The understanding of pathogenesis and treatment of basilar invagination has been evolving for over a century. The concepts regarding nature of atlantoaxial instability in such cases are also under discussion. The author presents personal evolving concepts on the subject. The technique of craniovertebral realigement, its rationale and the outcome of treatment is presented.

Key words: Atlantoaxial instability, basilar invagination, craniovertebral junction, craniovertebral realignment

\section{INTRODUCTION}

The surgical management of craniovertebral junction issues is complex due to the relative difficulty in accessing the region, critical relationships of neurovascular structures and the intricate biomechanical issues involved. Whilst a successful outcome is gratifying, the complications of surgery, however, are potentially lethal.

Occipitoatlantal joint is the center for stability and atlantoaxial joint is the center for mobility. These two joints form the centers for stability and of mobility of the most stable and most mobile regions of the body. The role of facets in the spinal stability is relevant in the entire spine and more particularly in the craniovertebral junction. The role of the facets in the spinal stabilization in general seems to be most ill-understood and therapeutically the strength of the facets is least exploited. Our studies have emphasized the significance of facetal distraction and fixation for the entire spine, particularly of the craniovertebral junction. ${ }^{[1-5]}$

Basilar invagination is significantly common in India and in the Indian subcontinent. Even in India, there is a disproportionately high incidence in north-western belt of the country. No genetic factor has been identified that could explain the discrepancy in incidence. Our

\begin{tabular}{|l|l|}
\hline \multicolumn{2}{|c|}{ Access this article online } \\
\hline Quick Response Code: & Website: \\
\hline & www.ijns.in \\
\cline { 2 - 2 } & \\
\hline
\end{tabular}

understanding in the subject suggests that muscular weakness of the neck due to protein-calorie mal-nutrition might be the key initiating factor in providing a foundation of instability that leads to formation of abnormality of basilar invagination. Poor delivery practices and excessive use of forceps may have a role in initial injury to the craniovertebral junction muscles leading to instability and initiation of the process of basilar invagination. Degeneration of the spine in general and craniovertebral junction in particular, all related to muscle weakness, can lead to instability and subsequently to basilar invagination. Some workers had related lifting of heavy weights on the head to spinal degeneration. Deficiency in specific vitamins has also been incriminated to be causative.

\section{BASILAR INVAGINATION CLASSIFICATION INTO GROUP A AND B}

Basilar invagination can be divided into two groups. ${ }^{[6]}$ In Group A basilar invagination there was clinical and radiological evidence of instability of the craniovertebral junction. The instability of the region is manifested by distancing of the odontoid process away from the anterior arch of the atlas. The tip of the odontoid process "invaginated" into the foramen magnum and was above the Chamberlain line, ${ }^{[7]}$ McRae line of foramen magnum ${ }^{[8]}$ and Thiebaut et al. clival line. ${ }^{[9]}$ The definition of basilar invagination of prolapse of the cervical spine into the base of the skull, as suggested by von Torklus and Gehle, ${ }^{[10]}$ was suitable for this group of patients [Figure 1]. We recently reported vertical mobile atlantoaxial dislocation wherein on flexion of the head the odontoid process invaginated into the foramen magnum like a piston. ${ }^{[11]}$ Vertical instability or basilar invagination is a result of

Address for correspondence: Prof. Atul Goel,

Department of Neurosurgery, King Edward VII Memorial Hospital and Seth G.S. Medical College, Parel, Mumbai - 400012 , Maharashtra,

India. E-mail: atulgoel62@hotmail.com 
incompetence of the lateral mass. The instability or basilar invagination can be grossly mobile and reducible or may be relatively fixed as a result of multiple naturally acting responses. Group B basilar invagination was where the odontoid process and clivus remained anatomically aligned despite the presence of basilar invagination and other associated anomalies. In this group, the tip of the odontoid process was above the Chamberlain's line but below the McRae's and the Wackenheim's lines [Figure 2]. The radiological findings suggested that the odontoid process in Group A patients resulted in direct compression of the brainstem. In this group, the atlantoaxial joints were oblique as shown in the figure [Figure 3], instead of the normally found horizontal orientation. We have found similarities of such a position of the C1-2 facets with spondylolisthesis seen in the subaxial spine. ${ }^{[12]}$ It appears that the atlantoaxial joint in such cases is in an abnormal position as a result of mechanical instability and progressive worsening of the dislocation is probably secondary to increasing "slippage" of the facets of atlas over the facets of axis. ${ }^{[12,13]}$ In Group B, the atlantoaxial joints were relatively normally aligned.

A number of bone and soft tissue anomalies are associated with basilar invagination. These include short neck, torticollis, platybasia, cervical vertebral body fusion (Klippel-Feil abnormality) ${ }^{[14]}$ including assimilation of atlas, spondylotic spinal changes and restriction of neck movements. A number of these abnormalities were seen to be reversible following decompression and stabilization of the region. ${ }^{[15]}$ Considering that several physical features associated with this group of basilar invagination are reversible, it appears that the pathogenesis in such cases may be more due to mechanical factors rather than congenital causes or embryological dysgenesis. The common teaching on the subject is that the short neck and torticollis are a result of embryological dysgenesis and effectively result in indentation of the odontoid process into the cervicomedullary cord. However, it appears that it is the cord compression due to indentation by the odontoid process that is the primary event and all the physical alterations and bony abnormalities, including the short neck and torticollis are secondary natural protective responses that aim to reduce the stretch of the cord over the indenting odontoid process. Pain, restriction of neck movements and hyperlordosis of the neck also indicate the presence of instability of the craniovertebral junction.

\section{CRANIOVERTEBRAL REALIGNMENT}

The standard treatment of Group A basilar invagination was considered to be transoral decompression [Figures 4 and 5]. ${ }^{[7,16]}$ Majority of authors recommend a posterior occipitocervical fixation following the anterior decompression. Trans-oral odontoidectomy and resection of superior half or third of the $\mathrm{C} 2$ body was a gratifying surgical procedure in Group A patients. ${ }^{[6,17]}$

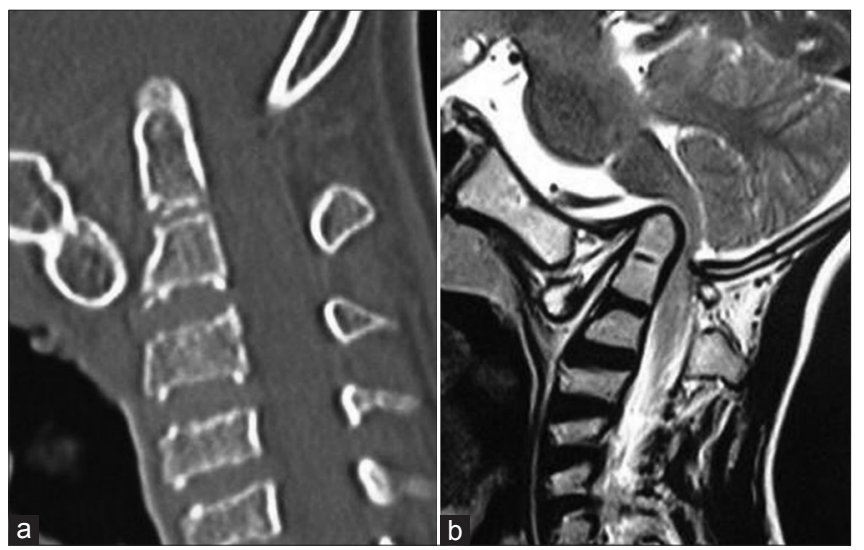

Figure 1: (a) Sagittal computed tomography scan showing Group A basilar invagination (b) Magnetic resonance imaging showing Group A basilar invagination

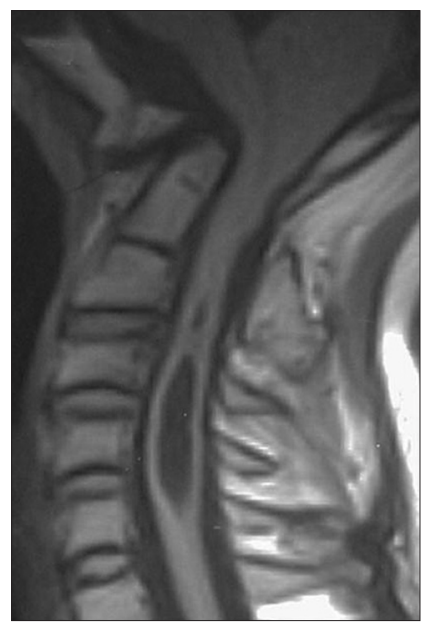

Figure 2: Magnetic resonance imaging showing Group B basilar invagination

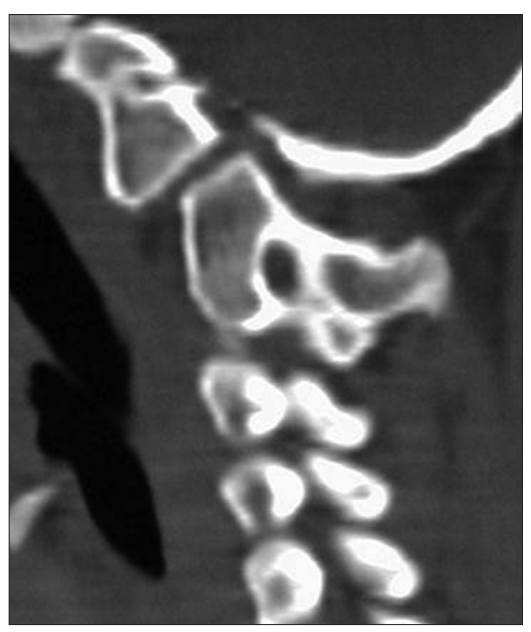

Figure 3: Sagittal image showing the spondylolisthesis of C1 facet over C2 facet as a cause of basilar invagination 


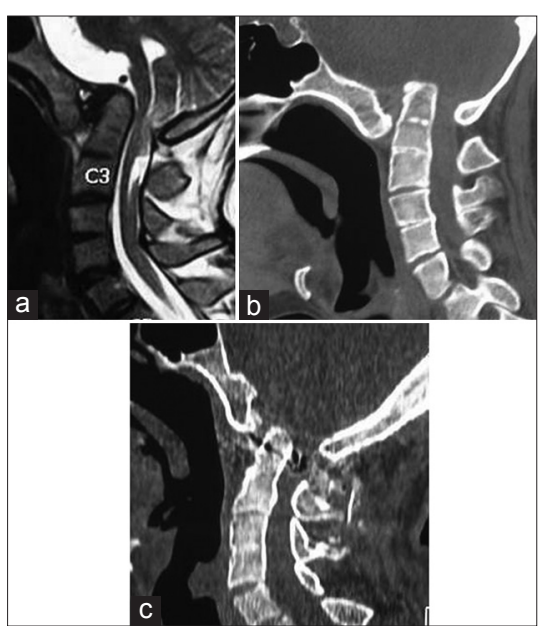

Figure 4: (a) Pre-operative magnetic resonance imaging scan showing marked Group A basilar invagination (b) Computed tomography scan showing the invagination (c) Post-operative computed tomography scan showing reduction of the basilar invagination surgically treated by the technique of atlantoaxial joint distraction, reduction and fixation

However, the long-term clinical outcome following the twin operation of transoral decompression followed by posterior stabilization was seen to be inferior to the clinical outcome following our current operation that involves craniovertebral realignment without any bone, dural or neural decompression.

We had earlier attempted to reduce basilar invagination by performing occipitocervical fixation following institution of cervical traction. ${ }^{[6,16]}$ However, it was consistently observed that reduction of the basilar invagination and of atlantoaxial dislocation could not be sustained by the implant. The technique of craniovertebral realignment by wide removal of atlantoaxial joint capsule and articular cartilage by drilling and subsequent distraction of the joint by manual manipulation provided a unique opportunity to obtain reduction of the basilar invagination and of atlantoaxial dislocation.

\section{TECHNIQUE OF ATLANTOAXIAL JOINT DISTRACTION AND CRANIOVERTEBRAL REALIGNMENT}

The facets of the joint on both sides are distracted using a combination of varying sizes of osteotomes and customized distractors. The osteotomes are introduced with the flat end and then turned inside the joint to affect distraction. Bone graft harvested from the iliac crest is stuffed into the distracted articular cavity. In majority of cases, only bone graft is used and stuffed into the joint cavity and is aimed to serve the purpose of distraction and of arthrodesis. In a selected group of patients, bone graft is packed in titanium metal spacers and bone graft and titanium spacer is used as a strut in the prepared

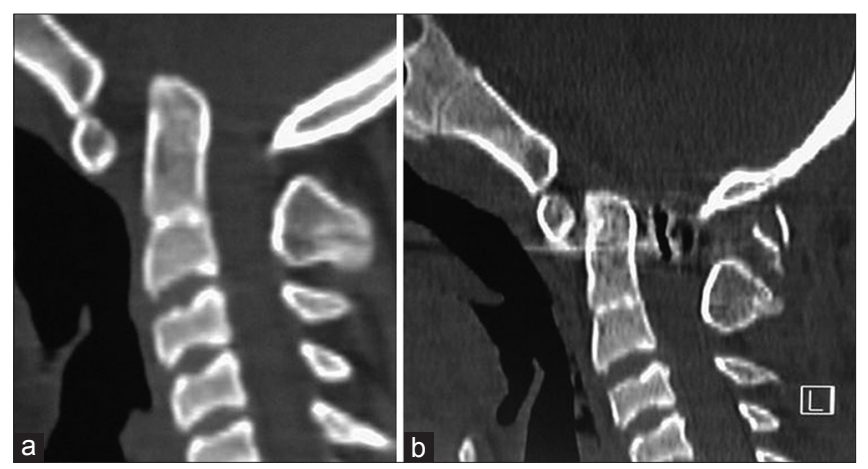

Figure 5: (a) Pre-operative computed tomography scan showing Group A basilar invagination (b) Post-operative scan showing reduction of the basilar invagination, without any bone or dural decompression

atlantoaxial facet joints. The size of the spacers used depends on the space available within the distracted joint space as well as the amount of distraction required to reduce the basilar invagination. The average sized spacers measured $10 \mathrm{~mm}$ in length, $8 \mathrm{~mm}$ in breadth and $3 \mathrm{~mm}$ in height. Metal spacer has a single large or multiple small holes that assist in bone fusion and is tapered at one end to assist placement in the joint. Bone graft was stuffed in the distracted joint space in multiple pieces on all the sides of the spacer. ${ }^{[1,18-20]}$

With our experience in handling the atlantoaxial joints in this group of patients, we have realized that the joint is not "fixed" or "fused" but is mobile and in most cases is hypermobile and is the prime cause for the basilar invagination. Prior to our current opinion about instability in basilar invagination, ${ }^{[21]}$ the atlantoaxial joint was considered to be fixed or fused. The history of trauma preceding the clinical events, predominant complaint of pain in the neck and the improvement in neurological symptoms following institution of cervical traction also suggests the presence of instability of the craniovertebral region. ${ }^{[11]}$

The fixation was seen to be strong enough to sustain the vertical, transverse and rotatory strains of the most mobile region of the spine. Following surgery, the alignment of the odontoid process and the clivus and the entire craniovertebral junction improved toward normalcy. The tip of the odontoid process receded in relationship to the Wackenheim's clival line, Chamberlain's line and McRae' line suggesting reduction in the basilar invagination. The posterior tilt of the odontoid process, as evaluated by modified omega angle, was reduced after the surgery. We could obtain varying degrees of reduction of the basilar invagination and atlantoaxial dislocation. The extent of distraction of the joint and the subsequent reduction in the basilar invagination was more significant in younger than in older patients. ${ }^{[18]}$ 


\section{TREATMENT OF BASILAR INVAGINATION AND ATLANTOAXIAL DISLOCATION IN CASES WITH RHEUMATOID ARTHRITIS}

Basilar invagination is commonly associated with atlantoaxial dislocation and the complex results in a significant degree of neck pain and myelopathy adding considerably to the disability secondary to affection of other joints. A number of treatment options are available in the treatment that includes drug therapy and non-operative treatment. We recently reported the feasibility of craniovertebral region bone alignment, distraction of the facets of atlas and axis and direct lateral mass plate and screw atlantoaxial fixation for management of both basilar invagination and atlantoaxial dislocation secondary to rheumatoid arthritis. ${ }^{[22,23]}$ Our operation of craniovertebral realignment and stabilization without any bone decompression could be successfully employed in cases with atlantoaxial dislocation in the presence or absence of retro-odontoid pannus and in cases with basilar invagination. The patients showed a remarkable and sustained neurological and radiological improvement.

It was recently demonstrated that following atlantoaxial joint distraction there was immediate post-operative reversal of retroodontoid pannus, in addition to reduction of the atlantoaxial dislocation and of basilar invagination. ${ }^{[24]}$ This finding suggests that retro-odontoid pannus, basilar invagination and atlantoaxial dislocation are all related to atlantoaxial joint arthritis, lateral mass "collapse" and reduction of the joint space. The laxity of the posterior longitudinal ligament results in its posterior bulging. The exact role of inflammation in the formation of the pannus needs to be re-evaluated. Distraction of the facets results in stretching of the posterior longitudinal ligament and reduction of the pannus and reduction of basilar invagination and atlantoaxial dislocation.

\section{FIXED OR IRREDUCIBLE ATLANTOAXIAL DISLOCATION}

Atlantoaxial dislocation is described as "fixed" or "irreducible" when there is no radiographic reduction of the dislocation on full neck extension or after institution of cervical traction. Fixed atlantoaxial dislocation can be congenital in nature or can be secondary to trauma to the region. Congenital os odontoideum and fracture at the base of the odontoid process are frequent accompaniments of fixed atlantoaxial dislocation. Degenerative arthritis of the atlantoaxial joint seems to be an important cause of "fixed" or "irreducible" atlantoaxial dislocation. Various authors have suggested a transoral decompression followed by a posterior fixation as the safest method of treatment of this complex anomaly. Treatment by posterior decompressive procedures has been reported to be associated with high complication rate. Some of the authors have reported success with a transoral decompression of the region, without any posterior fixation.

Direct facet joint distraction can result in reduction of the fixed dislocation in a significant number of cases. With our experience, it seems that there may be a place for reduction of the "fixed" atlantoaxial dislocation and a subsequent fixation, without the removal of any bony spinal element. ${ }^{[25]}$ Such a treatment can be adopted even is cases with "spondyloptosis" of atlas over axis. ${ }^{[26]}$ As there is no vertebral body of the atlas, spondyloptosis can be labeled as a clinical condition when the facet of atlas was dislocated anterior to the facet of axis.

\section{REFERENCES}

1. Goel A. Treatment of basilar invagination by atlantoaxial joint distraction and direct lateral mass fixation. J Neurosurg Spine 2004;1:281-6.

2. Goel A. Facet distraction spacers for treatment of degenerative disease of the spine: Rationale and an alternative hypothesis of spinal degeneration. J Craniovertebr Junction Spine 2010;1:65-6.

3. Goel A. Facet distraction-arthrodesis technique: Can it revolutionize spinal stabilization methods? J Craniovertebr Junction Spine 2011;2:1-2.

4. Goel A, Shah A. Facetal distraction as treatment for single- and multilevel cervical spondylotic radiculopathy and myelopathy: A preliminary report. J Neurosurg Spine 2011;14:689-96.

5. Goel A, Shah A, Jadhav M, Nama S. Distraction of facets with intraarticular spacers as treatment for lumbar canal stenosis: Report on a preliminary experience with 21 cases. J Neurosurg Spine 2011;19:627-7.

6. Goel A, Bhatjiwale M, Desai K. Basilar invagination: A study based on 190 surgically treated patients. J Neurosurg 1998;88:962-8.

7. Chamberlain WE. Basilar impression (Platybasia): A bizarre developmental anomaly of the occipital bone and upper cervical spine with striking and misleading neurologic manifestations. Yale J Biol Med 1939;11:487-96.

8. MCRAE DL. Bony abnormalities in the region of the foramen magnum: Correlation of the anatomic and neurologic findings. Acta radiol 1953;40:335-54.

9. Thiebaut F, Wackenheim A, Vrousos C. New median sagittal pneumostratigraphical finding concerning the posterior fossa. J Radiol Electrol Med Nucl 1961;42:1-7.

10. Von Torklus D, Gehle W. The Upper Cervical Spine: Regional Anatomy, Pathology, and Traumatology. A Systematic Radiological Atlas and Textbook. New York: Grune and Stratton; 1972. p. 1-98.

11. Goel A, Shah A, Rajan S. Vertical mobile and reducible atlantoaxial dislocation. Clinical article. J Neurosurg Spine 2009;11:9-14.

12. Kothari M, Goel A. Transatlantic odonto-occipital listhesis: The so-called basilar invagination. Neurol India 2007;55:6-7.

13. Goel A. Progressive basilar invagination after transoral odontoidectomy: Treatment by atlantoaxial facet distraction and craniovertebral realignment. Spine (Phila Pa 1976) 2005;30:E551-5.

14. Gunderson $\mathrm{CH}$, Greenspan RH, Glaser GH, Lubs HA. The Klippel-Feil syndrome: Genetic and clinical reevaluation of cervical fusion. Medicine (Baltimore) 1967;46:491-512.

15. Goel A, Shah A. Reversal of longstanding musculoskeletal changes in basilar invagination after surgical decompression and stabilization. J Neurosurg Spine 2009;10:220-7. 
16. Goel A, Achawal S. The surgical treatment of Chiari malformation association with atlantoaxial dislocation. Br J Neurosurg 1995;9:67-72.

17. Goel A, Desai K. Surgery for syringomyelia: An analysis based on 163 surgical cases. Acta Neurochir (Wien) 2000;142:293-301.

18. Goel A, Sharma P. Craniovertebral junction realignment for the treatment of basilar invagination with syringomyelia: Preliminary report of 12 cases. Neurol Med Chir (Tokyo) 2005;45:512-7.

19. Goel A, Laheri V. Plate and screw fixation for atlanto-axial subluxation. Acta Neurochir (Wien) 1994;129:47-53.

20. Goel A, Desai KI, Muzumdar DP. Atlantoaxial fixation using plate and screw method: A report of 160 treated patients. Neurosurgery 2002;51:1351-6.

21. Goel A. Instability and basilar invagination. J Craniovertebr Junction Spine 2012;3:1-2.

22. Goel A, Sharma P. Craniovertebral realignment for basilar invagination and atlantoaxial dislocation secondary to rheumatoid arthritis. Neurol India 2004;52:338-41.

23. Goel A, Pareikh S, Sharma P. Atlantoaxial joint distraction for treatment of basilar invagination secondary to rheumatoid arthritis. Neurol India 2005;53:238-40.

24. Goel A, Dange N. Immediate postoperative regression of retroodontoid pannus after lateral mass reconstruction in a patient with rheumatoid disease of the craniovertebral junction. Case report. J Neurosurg Spine 2008;9:273-6.

25. Goel A, Kulkarni AG, Sharma P. Reduction of fixed atlantoaxial dislocation in 24 cases: Technical note. J Neurosurg Spine 2005;2:505-9.

26. Goel A, Muzumdar D, Dange N. One stage reduction and fixation for atlantoaxial spondyloptosis: Report of four cases. Br J Neurosurg 2006;20:209-13.

How to cite this article: Goel A. Craniovertebral realignment for basilar invagination. Indian J Neurosurg 2013;2:229-33.

Source of Support: Nil, Conflict of Interest: None declared.

\section{Author Help: Online submission of the manuscripts}

Articles can be submitted online from http://www.journalonweb.com. For online submission, the articles should be prepared in two files (first page file and article file). Images should be submitted separately.

1) First Page File:

Prepare the title page, covering letter, acknowledgement etc. using a word processor program. All information related to your identity should be included here. Use text/rtf/doc/pdf files. Do not zip the files.

2) Article File:

The main text of the article, beginning with the Abstract to References (including tables) should be in this file. Do not include any information (such as acknowledgement, your names in page headers etc.) in this file. Use text/rtt/doc/pdf files. Do not zip the files. Limit the file size to $1 \mathrm{MB}$. Do not incorporate images in the file. If file size is large, graphs can be submitted separately as images, without their being incorporated in the article file. This will reduce the size of the file.

3) Images:

Submit good quality color images. Each image should be less than $4096 \mathrm{~kb}(4 \mathrm{MB})$ in size. The size of the image can be reduced by decreasing the actual height and width of the images (keep up to about 6 inches and up to about $1800 \times 1200$ pixels). JPEG is the most suitable file format. The image quality should be good enough to judge the scientific value of the image. For the purpose of printing, always retain a good quality, high resolution image. This high resolution image should be sent to the editorial office at the time of sending a revised article.

4) Legends:

Legends for the figures/images should be included at the end of the article file. 